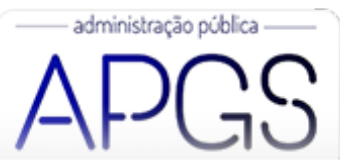

Administração Pública e Gestão Social ISSN: 2175-5787

apgs@ufv.br

Universidade Federal de Viçosa

Brasil

\title{
Resenha do livro "Inovação e Políticas Públicas: superando o mito da ideia"
}

\section{Flávio Tonelli, Dany}

Resenha do livro "Inovação e Políticas Públicas: superando o mito da ideia"

Administração Pública e Gestão Social, vol. 11, núm. 4, 2019

Universidade Federal de Viçosa, Brasil

Disponível em: http://www.redalyc.org/articulo.oa?id=351560525012

Esta obra está bajo una Licencia Creative Commons Atribución-NoComercial-SinDerivar 3.0 Internacional. 


\section{Resenha do livro "Inovação e Políticas Públicas: superando o mito da ideia"}

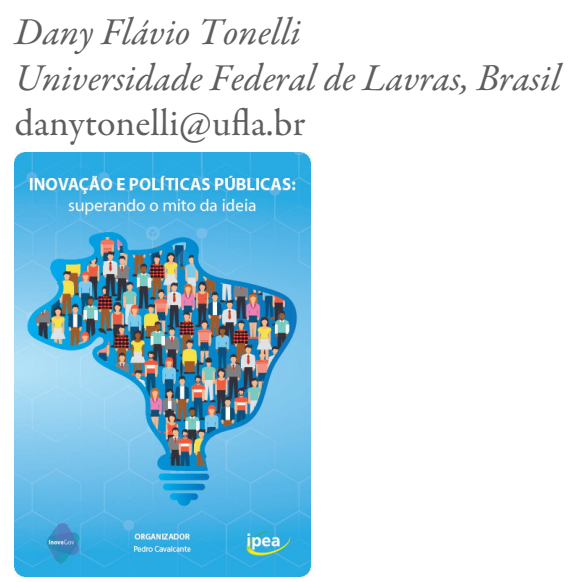

Dany Flávio Tonelli

danytonelli@ufla.br

Cavalcante Pedro. Inovação e Políticas Públicas: superando o mito da ideia. 2019. Brasil. Ipea. 436pp.. 978-85-7811-352-0

Não é recente o interesse pela inovação no setor público. Em duas décadas houve expressivo aumento de iniciativas como laboratórios, departamentos, políticas e prêmios dedicados ao tema. Tais iniciativas demonstram na prática a relevância de fatores críticos apresentados por Bason (2010), como, por exemplo, a conscientização da relevância da inovação pública para a superação dos desafios impostos por um ambiente em crescente complexidade, a capacitação da força de trabalho com métodos adequados ao contexto governamental e a cocriação que envolve agentes públicos e cidadãos na busca de soluções novas. Embora a inovação na prática tenha ocupado lugar relevante na agenda governamental, uma crítica recorrente diz respeito ao fato da produção teórica acerca da inovação no setor público não avançar no mesmo ritmo, o que tornaria o debate acadêmico ainda muito ancorado na teoria econômica e técnica da inovação. Se por um lado essa dificuldade limita o repertório conceitual, por outro, o fato de trazer à tona o "como fazer" e explorálo à luz das experimentações bem sucedidas é fundamental para inspirar e formar agentes de inovação nas organizações públicas e fomentar agendas de pesquisa vinculadas à essas realidades.

A obra organizada pelo especialista em políticas públicas e gestão governamental e pesquisador do IPEA Pedro Cavalcante (Cavalcante, 2019), insere-se nesse contexto de uma forma bastante positiva. A coletânea de 22 capítulos divide-se em cinco partes: (i) do design thinking à inovação; (ii) mix de métodos em prol da inovação; (iii) cocriação e coprodução: casos de inovação aberta; (iv) laboratórios de inovação: é testando que se inova e (v) gamificação: aprendizado interativo nas políticas públicas. Todos os capítulos são escritos por profissionais inseridos na carreira pública ou relacionados com esse ambiente. Dos 22 capítulos, 20 são dedicados a estudos de casos de experiências inovadoras. O objetivo é dar foco na implementação e nos métodos sobre como conduzir os processos de mudanças que vão resultar em novos serviços, processos, arranjos e políticas. De modo transversal, apesar da heterogeneidade de contextos estudados, temas de cocriação e coprodução, de aprendizado individual e coletivo e da experimentação perpassam todas as discussões. Também é possível perceber a utilidade do material para projetar agendas como a da pesquisa, em torno do avanço de uma teoria da inovação pública e a jurídica, em se tratando do risco de ir além dos ditames da burocracia.

Embora a coletânea se encontre no campo da descrição de casos, ela cumpre o propósito de servir como rica fonte de debate e aprendizado que contribui para a disseminação da cultura da inovação. Os casos munem profissionais com métodos para tornar ideias em ações concretas no enfrentamento dos problemas públicos. 
O estudioso pode recorrer ao material se o interesse for geral ou específico. Há ampla variedade de contextos e aplicações, da esfera municipal à federal, da região sul ao nordeste, nos campos da educação, gestão, saúde, assistência social e mobilidade, dentre outros.

$\mathrm{Na}$ primeira parte dedicada ao design thinking, a técnica é apresentada como centrada no ser humano e fundamentada no pensamento analítico e cocriativo, necessariamente envolvendo a construção coletiva de soluções para os problemas públicos. A esse respeito, a iniciativa se junta à percepção de estudiosos do tema sobre a necessidade de permitir ao setor público ir além das tradicionais respostas burocráticas e condicionadas ao cumprimento de regras predeterminadas. Em vez da realização de diagnósticos do passado para projetar o leque de alternativas futuras, o design thinking permitiria a imersão empática no problema público. Em vez de um olhar "de fora" e hierarquizado, o design thinking tornaria possível a percepção do problema a partir da perspectiva de quem o experimenta. A partir dessa discussão inicial e da definição de etapas para a aplicação da técnica, vários estudos de caso detalham o passo a passo de aplicar métodos cocriativos. A Escola das Mães da prefeitura de Santos (Macena; Alvarenga; Guimarães; Pessoa, 2019), por exemplo, é um conceito construído coletivamente que apresentou resultados muito positivos, inclusive na redução da taxa de mortalidade de recém-nascidos do município. Além deste, a seção apresenta outros casos. Por exemplo, o Hubgov (Cap. 3), uma iniciativa de coprodução aplicada por uma agência de consultoria privada em Santa Catarina; o caso da alteração do fluxo de processos em ambiente altamente burocrático na Casa Civil (Cap. 4) e a aplicação de design thinking na remodelagem do atendimento ao cidadão da ANVISA (Cap. 5). Todas experiências bem sucedidas e minuciosamente detalhadas, servindo de exemplos de como aplicar esses métodos em outros contextos.

A parte 2 "Mix de Métodos em Prol da Inovação" apresenta vários casos de melhorias de serviços públicos e geração de valor na perspectiva do cidadão-usuário baseando-se abordagens metodológicas diversas. Um exemplo bastante ilustrativo é o design etnográfico, praticado pelo laboratório de inovação da ENAP - Gnova - e aplicado em diferentes estágios do ciclo de diversas políticas políticas públicas (Cap. 7). Ele permite a inserção da percepção do usuário na equação da busca de soluções inovadoras. $\mathrm{O}$ texto apresenta diversas experiências de aplicação detalhada do método de inspiração etnográfica, as quais não apenas motivam interessados, mas oferecem instrumental para adaptar tais iniciativas em contextos específicos. Ainda nessa parte se encontram casos aplicados em contextos variados, que vão desde órgãos da administração federal a prefeituras como a de Juazeiro do Norte - CE. Neste (Cap. 9), a solução inovadora foi utilizar ao sistema de acreditação da Organização Nacional de Acreditação (ONA) como meio para melhorar a qualidade dos serviços prestados no Centro de Especialidades Odontológicas da cidade, melhorando seus processos internos, a eficiência de recursos e alcançando padrões de qualidade internacionais.

Na seção "Cocriação e Coprodução: casos de inovação aberta", o destaque está para as plataformas digitais e para a criação e compartilhamento de informações que podem servir tanto para melhorar a interação sociopolítica entre a sociedade e o legislativo - caso do laboratório Hacker da Câmara dos Deputados (Cap. 13) - como para fomentar a criação e a contratação de startups pela prefeitura de São Paulo para oferecimento de serviços gratuitos baseados nos dados de mobilidade - caso Mobilab (Cap. 16). Uma reflexão interessante nesses e nos demais casos discutidos relaciona-se à perda de sentido dos discursos que impõem fronteiras rígidas entre público e privado. As iniciativas colaborativas entre cidadãos, governos e empresas e a construção de arranjos cocriativos são fundamentais para a promoção de diversas políticas públicas. A inovação nesses arranjos colaborativos perpassa tanto pela busca de novos modelos organizacionais como em novos ordenamentos jurídicos.

A seção 4 dedica-se aos laboratórios governamentais de inovação. A institucionalização de espaços destinados a discutir ações criativas e potencialmente geradoras de valor público é mais do que um modismo. Os laboratórios se tornaram uma tendência bastante consistente em todos os níveis governamentais. Além do crescimento em número, o estudo de contextualizado de Cavalcante, Goellner e Magalhães (2019) também demonstra que esses espaços estão se institucionalizando, sendo a dimensão de gestão de pessoas considerada 
fator determinante e a disponibilidade de recursos principal indutor organizacional. São apresentados três experiências, o laboratório criado em 2012 pela ANAC - Inovanac (Cap. 18), o laboratório de inovação do governo do Espírito Santo (Cap. 19) e o Lab Inovases do Distrito Federal (Cap. 20). Todas refletem a relevância que a inovação vem adquirindo na agenda de políticas públicas e mostram que esses espaços são essenciais para a disseminação da cultura da inovação no setor público. O problema é que embora os resultados desses investimentos sejam positivos no longo prazo, o alcance desses resultados depende da sua continuidade. Nem sempre essa é uma característica marcante no setor público.

Finalmente, a última parte dedica-se a experiências de gamificação como aprendizado interativo nas políticas públicas. A gamificação surgiu como estratégia para motivar pessoas em torno da solução de problemas de modo atrativo em áreas como produtividade, finanças, saúde, educação, sustentabilidade, entre outros (Silva; Medeiros, 2019). Os dois casos apresentados nos capítulos finais são vastamente ilustrados e explicados, constituindo ricas fontes de informação e inspiração para entusiastas e simpatizantes das metodologias ativas de solução de problemas.

A constatação amplamente evidenciada pela diversidade de experiências apresentadas em diversos níveis de governo de várias regiões do Brasil é que a inovação pública passa por um processo de sedimentação que produz extensas mudanças. Do servidor burocrático clássico e do gerente tecnicamente preparado vê-se surgir um novo perfil profissional que reúne atributos de liderança e empreendedorismo com a sensibilidade aguçada para perceber e tentar superar os problemas críticos. Além disso, vê-se que a preocupação com a inovação está cada vez mais presente no cotidiano das organizações públicas. Em parte isso decorre das demandas dos ambientes econômico, tecnológico e sociopolítico, mas também das ações organizacionais deliberadas que colocam a busca por mudança e modernização nos mais elevados objetivos estratégicos. O problema é que os novos ordenamentos jurídicos quase sempre são consequência dos processos de mudança, o que expõe agentes públicos ao risco de atuar em campo desconhecido pelas regras da burocracia.

\section{REFERÊNCIAS}

Bason, C. (2010). Leading Public Innovation: co-creation for a better society. Chicago: Policy Press, 278 p.

Cavalcante, P (Org.). (2019). Inovação e Políticas Públicas: superando o mito da ideia. Brasília: IPEA, 427 p.

Cavalcante, P.; Goellner, I. D. A.; Magalhães, A. G. (2019). Perfis e características das equipes e dos laboratórios de inovação no Brasil. In: Cavalcante, P. (Ed.). Inovação e Políticas Públicas: superando o mito da ideia, cap. 17, p. $315-340$.

Macena, A.; Alvarenga, C.; Guimarães, G.; Pessoa, L. Escola das mães: como o design thinking contribuiu para diminuir as taxas de mortalidade infantil no município de Santos. In: Cavalcante, P. (Ed.). (2019). Inovação e políticas públicas: superando o mito da ideia. Brasília: IPEA, cap. 2, p. 29-52.

Silva, G. H. T.; Medeiros, C. (2019). Jogo da regulação: gamificação e design thinking para gerar empatia e experiências de aprendizado no ambiente regulatório. In: Cavalcante, P. (Ed.). Inovação e Políticas Públicas: superando o mito da ideia. Brasília: IPEA, cap. 21, p. 391 - 408.

\section{BY-NC-ND}

